\title{
Relationships between phenotypic variation in osmotic adjustment, water-use efficiency, and drought tolerance of seven cultivars of Lotus corniculatus L.
}

\author{
Luis Inostroza ${ }^{1 *}$, Hernán Acuña ${ }^{2}$, and Gerardo Tapia ${ }^{1}$
}

\begin{abstract}
Lotus corniculatus L. is a perennial forage legume species highly-adapted to growth under drought conditions. However, the genetic and physiological mechanisms involved in its adaptive capacity have not been elucidated. The role of osmotic adjustment (OA) and water-use efficiency (WUE) on the drought tolerance of L. corniculatus was studied in a greenhouse experiment. Seven cultivars of different origin were subjected to two contrasting treatments of available soil water: No water stress (NWS) and with water stress (WWS). Xylem water potential $\left(\Psi_{\mathrm{x}}\right)$, osmotic potential $\left(\Psi_{\pi}\right)$, pressure potential $\left(\Psi_{\mathrm{p}}\right)$, relative water content $(\mathrm{RWC})$, stomatal conductance $\left(\mathrm{g}_{\mathrm{s}}\right)$, shoot DM production, water transpiration $(\mathrm{T})$, and WUE (shoot DM/T) were measured. Water treatments significantly $(\mathrm{P}<0.05)$ affected plant water status, which was reflected in reduced $\Psi_{\mathrm{x}}, \mathrm{RWC}, \mathrm{g}_{\mathrm{s}}$, and transpiration rate in the WWS treatment compared with the NWS treatment. All cultivars showed a high capacity for OA under WWS treatment because $\Psi_{\pi}$ decreased by approximately $60 \%$ and $\Psi_{\mathrm{p}}$ increased by approximately $30 \%$, compared with the NWS treatment. Cultivars with a higher solute accumulation (low $\Psi_{\pi}$ value) had the lowest DM production under WWS treatment. In contrast, WUE varied greatly among cultivars and was positively associated $\left(R^{2}=0.88 ; \mathrm{P}<0.01\right)$ with $\mathrm{DM}$ production under drought conditions.
\end{abstract}

Key words: Drought acclimation, genetic variability, physiological traits, transpiration rate.

\section{INTRODUCTION}

Drought is the most important abiotic stress that curtails plant growth and crop productivity (Cobb et al., 2013). This has prompted the urgent need to understand the genetic and physiological mechanisms that induce plants to tolerate water deficit and to transfer this knowledge for increasing crop productivity in environments where water resources are a limiting factor.

Plants have developed a series of physiological mechanisms to tolerate drought (Cattivelli et al., 2008). Many of these only temporarily protect against dehydration and/or help plant survival and their role is controversial (Turner et al., 2007). Only a few mechanisms have been demonstrated to stabilize crop yield under drought conditions (Rebetzke et al., 2002; Kraakman et al., 2004): Osmotic adjustment (OA) and water-use efficiency (WUE) are two important physiological mechanisms to maintain the growth and productivity of plants under drought conditions (Babu et al., 1999; Richards et al., 2002). Osmotic adjustment

${ }^{1}$ Instituto de Investigaciones Agropecuarias, INIA Quilamapu, Av. Vicente Méndez 515, Chillán, Chile.

*Corresponding author (linostroza@inia.cl).

${ }^{2}$ Universidad de Concepción, Facultad de Agronomía, Av. Vicente Méndez 595, Chillán, Chile.

Received: 23 September 2014.

Accepted: 2 December 2014.

doi:10.4067/S0718-58392015000100001 involves actively accumulating solutes at the cellular level in response to a decline in plant water potential. As a result of this accumulation, the cell osmotic potential decreases, which in turn attracts water into the cell and maintains turgor pressure. This allows the conservation of physiological processes that depend on cellular turgor, such as expansive growth and stomatal control (Babu et al., 1999; Cattivelli et al., 2008). Furthermore, accumulated compatible solutes can also protect specific cellular functions either by stabilizing proteins or by scavenging reactive oxygen produced as a response to drought (Sanchez et al., 2008). In plant breeding, WUE has been one of the few physiological mechanisms that have allowed the selection of high production genotypes under drought conditions (Condon et al., 2004; Sinclair et al., 2004). From the physiological perspective, WUE is defined as the assimilation of $\mathrm{CO}_{2}$ per unit of transpired water (Condon et al., 2004). However, from an agronomic point of view, WUE is an econometric term derived from the marginal productivity theory: production (biomass) per unit of input (water); however, it encompasses a series of physiological processes, given that the physiological WUE depends on the balance between stomatal conductance $\left(\mathrm{g}_{\mathrm{s}}\right)$ and the photosynthetic capacity of the plant (Earl, 2002; Condon et al., 2004; Inostroza and Acuña, 2010).

In drought-prone environments, some species of the Lotus genus have been suggested to be a promising genetic resource, given their high forage yield potential and high capacity to adapt to marginal environments (Striker et al., 
2005; Teakle et al., 2006; 2007; Real et al., 2008; Garcia et al., 2008; Manzur et al., 2009; Teakle et al., 2010; Striker et al., 2012). Lotus corniculatus is a perennial forage legume that originates in the Mediterranean Basin and North Africa (Kirkbride, 1999) and has been widely used in southern Europe, North and South America, and New Zealand. It is established as a monocrop for hay or accompanied with grass when used for grazing. It is also used for soil remediation and erosion control. It is a particularly suitable legume for marginal soils and extensive grassland management systems, where it outperforms alfalfa (Medicago sativa L.) and white clover (Trifolium repens L.), the most popular temperate climate forage legumes (Carter et al., 1997).

Despite the well-known adaptive attributes of L. corniculatus, research is limited concerning the physiological mechanisms that cause drought tolerance. Only four studies have dealt with drought tolerance of the species. Carter et al. (1997) used L. corniculatus as a representative model of perennial legume species to study the effects of climatic change (temperature, $\mathrm{CO}_{2}$, and drought) on plant growth and productivity. The results of these studies showed that the species has the capacity to respond to drought by modifying its growth rate, leaf area, and biomass allocation. Neal et al. (2011) characterized WUE of 15 perennial forage species under field conditions in New South Wales, Australia, and showed that $L$. corniculatus reached a higher WUE than white clover and alfalfa under restrictive soil moisture conditions. Borsani et al. (2001) studied the effects of drought on $L$. corniculatus at the molecular level and demonstrated that drought induces oxidative stress in L. corniculatus leaves. As a consequence, total superoxide dismutase activity increases in plants as an antioxidant protector, after a 4-h drought treatment. Although this study is interesting, its scope is limited because it represents a short-term application of extreme water stress. This does not occur in the field and neither does it represent the dynamics of perennial forage species that suffer the consequences of stress at an advanced development stage; they are also subjected to cutting and animal grazing, where regrowth capacity plays a fundamental role in plant acclimation to drought. Sanchez et al. (2012) studied L. corniculatus drought tolerance from the perspective of its metabolism. Their results show that the accumulation of compatible osmolytes at the cellular level in response to drought is a tolerance mechanism of L. corniculatus and other agronomically and genetically important Lotus species. They also demonstrated that most synthesized metabolites are species-specific and fulfill different roles within each species. However, the study only has a metabolic scope and does not explore the role of the mechanisms on plant productivity. The study by Sanchez et al. (2012) is the first evidence of the ability of $L$. corniculatus to perform accumulation of solute.

The objectives of this experiment were to describe the role of OA and WUE on L. corniculatus drought tolerance and biomass productivity. The study analyzes the effect of gradual soil moisture loss and the application of drought treatment on plant regrowth; this is a relevant condition for perennial forage species; genetic variability is explored in terms of these physiological mechanisms in seven L. corniculatus cultivars with different origins.

\section{MATERIALS AND METHODS}

The experiment was carried out in pots under greenhouse conditions at Instituto de Investigaciones Agropecuarias, INIA Quilamapu, Chillán, Chile. The treatments included all factorial combinations of seven L. corniculatus cultivars and two levels of soil water availability. During May 2008, a number of seeds of each cultivar were individually sown in $27-\mathrm{cm}^{3}$ capacity seedbeds containing peat as a substrate (Biolan, Kauttua, Finland). Seedlings were inoculated, 1 wk after emergence, with a Mesorhizobium loti suspension. In winter (June and July), plants were grown in a greenhouse with heating and artificial light. At the beginning of spring (August) they were moved to a shed.

On 10 November 2008, when plants reached the five-leaf fully expanded developmental stage, they were transplanted into $3.5 \mathrm{~L}$ pots $(25 \mathrm{~cm}$ diameter $)$ containing soil derived from volcanic ash (medial, thermic, Humic Haploxerands, Andisol, according USDA soil taxonomy) of silty loam texture, as a substrate, and were moved to the greenhouse. All the pots contained $3 \mathrm{~kg}$ of soil homogenized by sieving without fertilizer application. Five plants of each cultivar were established in each pot. Temperature and relative humidity were controlled with a forced-air cooling system. These variables were recorded at 15-min intervals throughout the experiment with an automatic sensor (Hobo pro series, Onset Computer Corporation, Bourne, Massachusetts, USA). The greenhouse remained at a mean temperature and relative humidity of $23 / 16^{\circ} \mathrm{C}$ (day/night) and $50 / 75 \%$ (day/night), respectively.

\section{Lotus corniculatus cultivars}

Six L. corniculatus cultivars introduced from USA ('Norcen', 'Empire', and 'Steadfast'), Australia ('Ges5'), Brazil ('San Gabriel'), Uruguay ('Ganador'), and one Chilean cultivar ('Quimey') were used in the study. 'Quimey', 'Ganador', and 'San Gabriel' have an erect growth habit, whereas the others are semi-erect (Acuña et al., 2002).

\section{Growth environment and water stress treatments}

Two soil water treatments were established according to Inostroza and Acuña (2010). Treatments were: no water stress (NWS) and with water stress (WWS), where soil moisture remained at $54 \%$ and $25 \%$ (dry soil basis) and a water potential of -0.01 and $-0.5 \mathrm{MPa}$, respectively. To 
maintain moisture levels the weight of pots with soil and water was determined for each water treatment, by daily weighing and the replacement of transpired water. All pots were watered after transplantation, until the NWS treatment weight was reached, to ensure plant survival. A 3-cm layer of expanded polystyrene beads was also added to each pot to prevent soil water evaporation. The substrate weight in the root of each plant and the weight of the expanded polystyrene sheet were added to the total pot weight in each treatment. Subsequently, pots in the WWS treatment were not watered until they reached their corresponding weight (Figure 1). By recording the pot weight before and after irrigation, the appropriate amount of water transpired by the plants was then replaced daily (between 08:00 and 10:00 h).

The experiment was conducted in two periods. The first period was $30 \mathrm{~d}$ after planting (DAP), during which the effectiveness of the water treatments was evaluated by determining the relative water content (RWC), xylem water potential in stems $\left(\Psi_{\mathrm{x}}\right)$, osmotic potential $\left(\Psi_{\pi}\right)$, stomatal conductance $\left(\mathrm{g}_{\mathrm{s}}\right)$, and daily transpiration rate. At the end of this period, plants were cut $3 \mathrm{~cm}$ above the soil surface to evaluate shoot DM production (leaves + stems). One replicate was used destructively after this cutting to quantify the gain in root weight. This information was used to correct the pot weight during the second experimental period. The second period began after the cutting and lasted for $27 \mathrm{~d}$. The following traits were evaluated during this stage: RWC, $\Psi_{\mathrm{x}}, \Psi_{\pi}, \mathrm{g}_{\mathrm{s}}$, specific leaf area, and water transpiration (T). Finally, shoot and root DM (57 DAP) production was quantified. Water-use efficiency was estimated during both periods as the relationship between shoot DM and accumulated T during each experimental period.

\section{Evaluation methodologies}

In each pot, $g_{s}$ was evaluated with a porometer (AP4, Delta-T Devices, Cambridge, UK) in the central leaflet of three fully expanded leaves located in the top third of the

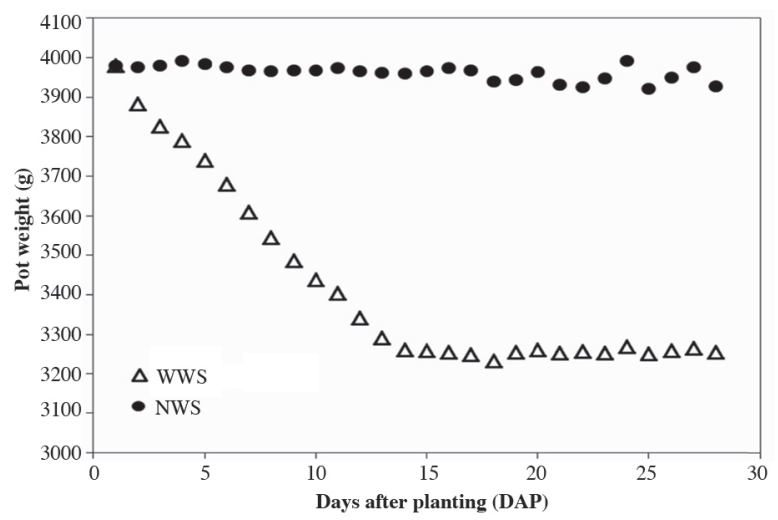

Figure 1. Weight loss of pots exposed to treatment with water stress (WWS) compared with no water stress (NWS) treatment. Values are means of seven Lotus corniculatus cultivars. plant. One stem from each pot was evaluated for $\Psi_{\mathrm{x}}$ by wrapping the stem with plastic film and covering it with aluminum foil $2 \mathrm{~h}$ before the measurement. Subsequently, the stem was removed by cutting the plant with a scalpel to determine $\Psi_{\mathrm{x}}$ with a Scholander type pressure pump. The osmotic potential was determined in a sample of eight leaves at a similar developmental stage in each pot. Leaves were extracted from the plant, immediately frozen in liquid nitrogen, and stored at $-40{ }^{\circ} \mathrm{C}$ until evaluation. A $20-\mu \mathrm{L}$ aliquot of cell liquid was later extracted using pressure. The osmolarity of the solution was determined with an osmometer (Model 3320, Advanced Instruments, Norwood, Massachusetts, USA) and $\Psi_{\pi}$ was calculated by van't Hoff law: $\Psi_{\pi}=-n \times T \times R$, where $n$ is osmolarity, $T$ is the absolute temperature, and $R$ is the gas constant. The pressure potential $\left(\Psi_{\mathrm{p}}\right)$ was then calculated as $\Psi_{\mathrm{x}}-\Psi_{\pi}$.

The RWC was determined according Inostroza and Acuña (2010) by the following expression:

$\mathrm{RWC}=(\mathrm{FW}-\mathrm{DW} / \mathrm{FTW}-\mathrm{DW}) \times 100 \mathrm{RWC}$

where FW and DW are the fresh and dry weight, respectively, and FTW is the weight at full turgor. After determining FTW, leaf area was measured with a leaf area meter (CI-202, CID Bio-Science Inc., Camas, Washington, USA). Specific leaf area was calculated based on this information (SLA = leaf area/leaf DM). All the evaluations were performed on clear days between 12:00 and 14:00 h.

Dry-matter production was determined by drying tissues (leaves, stems, and roots) in a forced-air oven at $65{ }^{\circ} \mathrm{C}$ until constant weight was reached. Roots were separated from the substrate by washing them under running water in a 27-mesh sieve. The sum of shoot DM measured in the two periods was considered total shoot $\mathrm{DM}$, and using this value, the root/total shoot DM ratio was determined. The leaf-weight ratio (LWR = Leaf DM/ Shoot DM) and leaf-area ratio $(\mathrm{LAR}=\mathrm{SLA} \times \mathrm{LWR})$ were calculated using the DM production data for the second period. The transpiration rate $\left(g\right.$ water $\left.\mathrm{d}^{-1}\right)$ was the slope of the linear regression between transpired water and time (DAP).

\section{Experimental design and statistical analyses}

A randomized complete block design with a factorial arrangement (two water levels and seven L. corniculatus cultivars) and four replicates was used. Data were analyzed by ANOVA and means were compared by the Least Significant Difference (LSD) test. The relationship among variables was analyzed by correlation and linear regression analysis with SAS (SAS Institute Inc., Cary, North Carolina, USA).

\section{RESULTS}

\section{Water treatments and plant water status}

The experiment began with the same level of water availability (NWS treatment) in all pots, to promote 
plant establishment and allow a gradual transition to the WWS treatment. Figure 1 shows the kinetics of water losses in the WWS treatment which reached the expected soil water deficit, at approximately 14 DAP. The transpiration rate showed differences between water treatments from 5 DAP, being 15\% lower in the WWS treatment compared with the NWS treatment (Figure 2). At 14 DAP, the difference increased to $40 \%$ (Table 1). The accumulated $\mathrm{T}$ during the first experimental period showed a highly significant Cultivar $\times$ Water treatment

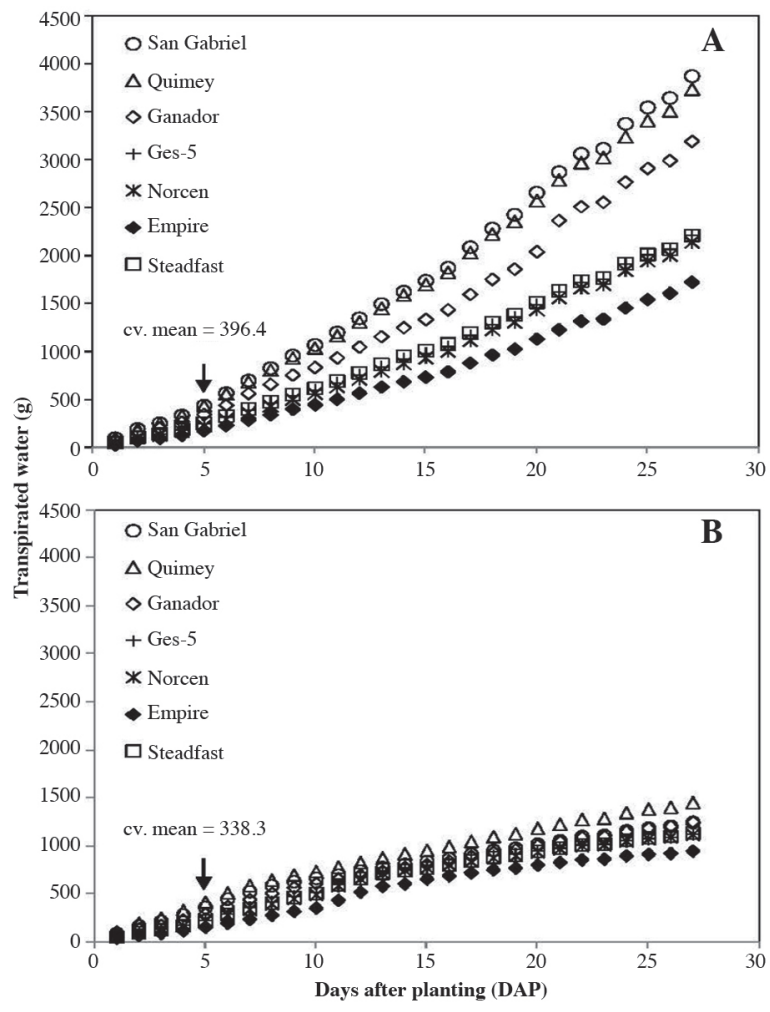

Figure 2. Daily accumulated transpiration of seven Lotus corniculatus cultivars exposed to treatments with water stress (A) or no water stress (B) under greenhouse conditions during the first experimental period. interaction ( $\mathrm{P}<0.001)$. Only 'Quimey' and 'Empire' were different in the WWS treatment $(\mathrm{P}<0.05)$, exhibiting the highest and lowest accumulated $\mathrm{T}$, respectively. In contrast, in the NWS treatment, the accumulated $\mathrm{T}$ of the South American cultivars ('Quimey', 'Ganador', and 'San Gabriel') considerably exceeded that of the other cultivars (Table 1). The accumulated $\mathrm{T}$ in the second experimental period also showed a significant Cultivar $\times$ Water treatment interaction $(\mathrm{P}<0.05)$. Accumulated $\mathrm{T}$ in the NWS treatment was $25 \%$ higher in the first period, and in the WWS treatment it was the same in both periods (Table 1). The reduction in accumulated $\mathrm{T}$ caused by the WWS treatment during the second experimental period was more severe than in the first one, with fluctuations between 57\% ('Ganador') and 72\% ('Empire'). 'Quimey' and 'Empire' showed the highest and the lowest accumulated $\mathrm{T}$, respectively, in both WWS and NWS treatments (Table 1).

The transpiration rate during the first experimental period also showed a highly significant Cultivar $\times$ Water treatment interaction $(\mathrm{P}<0.001$, Table 1$)$ and fluctuated in the NWS treatment between 65.4 ('Empire') and 148.6 ('San Gabriel') $g$ water $\mathrm{d}^{-1}$. During the second period there was not significant interaction Cultivar $\times$ Water treatment and a highly significant effect was observed in the soil-water treatments and cultivars $(\mathrm{P}<0.001)$. The transpiration rate was approximately $9 \%$ and $28 \%$ higher in the first experimental period in the WWS and NWS treatments, respectively. 'San Gabriel' and 'Quimey' had the highest transpiration rate, whereas 'Empire' had the lowest one.

The value of $\Psi_{\mathrm{x}}$ evaluated during the first experimental period (23 DAP) was almost six-fold less in the WWS treatment than in the NWS treatment $(\mathrm{P}<0.001)$, but no significant differences were observed among cultivars (Table 2). In the same period, RWC showed a significant Cultivar $\times$ Water treatment interaction $(\mathrm{P}<0.05$; Table 1$)$. The RWC of 'Empire', 'Steadfast', 'Ges-5', and 'Norcen' decreased by approximately $13 \%$ in the WWS treatment compared with the NWS treatment. 'San Gabriel' was

Table 1. Accumulated water transpiration ( $T$ ), transpiration rate, relative water content (RWC), and stomatal conductance ( $g_{s}$ ) of seven Lotus corniculatus cultivars exposed to two water treatments (NWS and WWS, without or with water stress, respectively) under greenhouse conditions.

\begin{tabular}{|c|c|c|c|c|c|c|c|c|c|c|c|c|c|c|}
\hline \multirow[b]{3}{*}{ Cultivars } & \multicolumn{6}{|c|}{ Accumulated T } & \multicolumn{4}{|c|}{ Transpiration rate } & & & & \\
\hline & \multicolumn{2}{|c|}{14 DAP } & \multicolumn{2}{|c|}{ Exp. Period I } & \multicolumn{2}{|c|}{ Exp. Period II } & \multicolumn{2}{|c|}{ Exp. Period I } & \multicolumn{2}{|c|}{ Exp. Period II } & \multicolumn{2}{|c|}{ RWC } & \multicolumn{2}{|c|}{$\mathrm{g}_{\mathrm{S}}$} \\
\hline & NWS & WWS & NWS & WWS & NWS & WWS & NWS & WWS & NWS & WWS & NWS & WWS & NWS & WWS \\
\hline & & \multicolumn{2}{|c|}{$\mathrm{g}$ water per pot } & & & & \multicolumn{2}{|c|}{ g water $\mathrm{d}^{-1}$} & & \multicolumn{2}{|c|}{$\%$} & \multicolumn{2}{|c|}{$\mathrm{mmol} \mathrm{m} \mathrm{m}^{-2} \mathrm{~s}^{-1}$} \\
\hline San Gabriel & 2093 & 912 & 3876 & 1244 & 4342 & 1338 & 148.6 & 42.2 & 166.2 & 52.4 & 0.90 & 0.83 & 436.8 & 78.0 \\
\hline Quimey & 2036 & 1047 & 3739 & 1453 & 4262 & 1605 & 143.1 & 49.6 & 163.1 & 63.2 & 0.89 & 0.85 & 601.7 & 75.8 \\
\hline Ganador & 1601 & 890 & 3196 & 1249 & 3570 & 1547 & 121.4 & 44.6 & 138.4 & 60.5 & 0.84 & 0.86 & 630.0 & 159.0 \\
\hline Empire & 897 & 719 & 1740 & 946 & 3438 & 946 & 65.4 & 38.5 & 133.0 & 35.9 & 0.84 & 0.75 & 530.4 & 161.9 \\
\hline Steadfast & 1201 & 842 & 2214 & 1134 & 3482 & 983 & 84.4 & 43.4 & 135.2 & 36.8 & 0.88 & 0.71 & 447.5 & 266.0 \\
\hline GES-5 & 1174 & 863 & 2219 & 1122 & 3403 & 1078 & 84.3 & 43.0 & 132.6 & 41.3 & 0.91 & 0.78 & 507.9 & 133.4 \\
\hline Norcen & 1122 & 839 & 2145 & 1118 & 3672 & 1170 & 81.9 & 43.0 & 142.8 & 45.5 & 0.86 & 0.78 & 459.6 & 221.8 \\
\hline Significance & \multicolumn{2}{|c|}{$* * *$} & \multicolumn{2}{|c|}{$* * *$} & \multicolumn{2}{|c|}{$*$} & \multicolumn{2}{|c|}{$* * *$} & \multicolumn{2}{|c|}{ ns } & \multicolumn{2}{|c|}{$*$} & \multicolumn{2}{|c|}{$*$} \\
\hline LSD & \multicolumn{2}{|c|}{182.6} & \multicolumn{2}{|c|}{362.8} & \multicolumn{2}{|c|}{385.9} & \multicolumn{2}{|c|}{14.3} & \multicolumn{2}{|c|}{16.4} & \multicolumn{2}{|c|}{0.072} & \multicolumn{2}{|c|}{153.70} \\
\hline
\end{tabular}

Least significant difference (LSD) of the Cultivar $\times$ Water treatment interaction. Significant at $* \mathrm{P}<0.05, * * \mathrm{P}<0.01$, and $* * * \mathrm{P}<0.001$.

DAP: Days after planting. 
Table 2. Xylem water potential $\left(\Psi_{\mathrm{x}}\right)$, osmotic potential $\left(\Psi_{\pi}\right)$, and pressure potential $\left(\Psi_{\mathrm{p}}\right)$ of seven Lotus corniculatus cultivars exposed to two water treatments (NWS and WWS, without or with water stress, respectively) under greenhouse conditions, evaluated 23 , 49 , and 56 d after planting (DAP).

\begin{tabular}{|c|c|c|c|c|c|c|c|c|c|}
\hline \multirow[b]{2}{*}{ Cultivars } & \multicolumn{3}{|c|}{23 DAP } & \multicolumn{3}{|c|}{49 DAP } & \multicolumn{3}{|c|}{56 DAP } \\
\hline & $\Psi_{\mathrm{X}}$ & $\Psi_{\pi}$ & $\Psi_{\mathrm{p}}$ & $\Psi_{\mathrm{X}}$ & $\Psi_{\pi}$ & $\Psi_{\mathrm{p}}$ & $\Psi_{\mathrm{X}}$ & $\Psi_{\pi}$ & $\Psi_{\mathrm{p}}$ \\
\hline & & & & & $\mathrm{MPa}$ & & & & 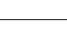 \\
\hline San Gabriel & -0.66 & -1.43 & 1.37 & -0.38 & -1.49 & 1.11 & -0.43 & -1.72 & 1.29 \\
\hline Quimey & -0.48 & -1.47 & 1.42 & -0.39 & -1.45 & 1.06 & -0.39 & -1.65 & 1.26 \\
\hline Ganador & -0.48 & -1.45 & 1.40 & -0.47 & -1.54 & 0.92 & -0.51 & -1.73 & 1.22 \\
\hline Empire & -0.43 & -1.67 & 1.63 & -0.37 & -1.63 & 1.17 & -0.50 & -1.89 & 1.39 \\
\hline Steadfast & -0.55 & -1.35 & 1.30 & -0.34 & -1.54 & 1.20 & -0.39 & -1.63 & 1.23 \\
\hline GES-5 & -0.56 & -1.51 & 1.46 & -0.39 & -1.55 & 1.16 & -0.32 & -1.82 & 1.50 \\
\hline Norcen & -0.49 & -1.57 & 1.53 & -0.32 & -1.62 & 1.30 & -0.37 & -1.81 & 1.43 \\
\hline Significance & $\mathrm{ns}$ & ns & ns & ns & $*$ & ns & ns & $*$ & ns \\
\hline LSD & $\mathrm{ns}$ & ns & ns & ns & 0.122 & ns & ns & 0.175 & $\mathrm{~ns}$ \\
\hline \multicolumn{10}{|c|}{ Water treatments } \\
\hline NWS & -0.15 & -1.09 & 1.08 & -0.26 & -1.21 & 0.95 & -0.29 & -1.43 & 1.14 \\
\hline WWS & -0.89 & -1.90 & 1.81 & -0.51 & -1.88 & 1.37 & -0.54 & -2.07 & 1.53 \\
\hline Significance & $* * *$ & $* * *$ & $* * *$ & $* * *$ & $* * *$ & $* * *$ & $* * *$ & $* * *$ & $* * *$ \\
\hline LSD & 0.170 & 0.095 & 0.100 & 0.103 & 0.065 & 0.129 & 0.126 & 0.094 & 0.153 \\
\hline
\end{tabular}

Significant at $* \mathrm{P}=0.05, * * \mathrm{P}=0.01$, and $* * * \mathrm{P}=0.001$; ns: nonsignificant; LSD: least significant difference.

the only South American cultivar that showed a decrease in RWC in the WWS treatment (8\%), whereas 'Quimey' and 'Ganador' did not show any significant differences in RWC between either water treatments (Table 1). Stomatal conductance $\left(\mathrm{g}_{\mathrm{s}}\right)$ also showed a significant Cultivar $\times$ Water treatment interaction $(\mathrm{P}<0.05$; Table 1$)$. Not all cultivars adjusted $\mathrm{g}_{\mathrm{s}}$ to the same degree; for example, it decreased more than $80 \%$ in 'San Gabriel' and 'Quimey', but only by $40 \%$ in 'Steadfast' in the WWS treatment compared with the NWS treatment (Table 1). 'Quimey' showed one of the highest $g_{s}$ values in the NWS treatment, whereas it had the lowest $g_{s}$ in the WWS treatment (Table 1).

Xylem water potential $\left(\Psi_{\mathrm{x}}=\Psi_{\pi}+\Psi_{\mathrm{p}}\right)$ and its osmotic $\left(\Psi_{\pi}\right)$ and pressure $\left(\Psi_{\mathrm{p}}\right)$ components were evaluated three times during the experiment (Table 2). For all potentials $\left(\Psi_{\mathrm{x}}, \Psi_{\pi}, \Psi_{\mathrm{p}}\right)$ and evaluation dates, a highly significant effect was observed for the soil-water treatments $(\mathrm{P}<0.001)$. Significant differences were observed only between cultivars in $\Psi_{\pi}$ values at 49 and 56 DAP (Table 2). Xylem water potential values stabilized at about -0.28 and $-0.52 \mathrm{MPa}$ in the NWS and WWS treatments, respectively, during the second experimental period (49 and 56 DAP) (Table 2).

\section{Dry matter production and partitioning}

Dry matter production evaluated during the first and second experimental periods showed a significant Cultivar $\times$ Water treatment interaction $(\mathrm{P}<0.05$; Table 3$)$. In the first period DM production in 'Quimey' decreased by $60 \%$ in the WWS treatment compared with in the NWS treatment, whereas it decreased by approximately $80 \%$ in 'Empire'. The DM production of the South American cultivars in the NWS treatment was considerably higher $(\mathrm{P}<0.05)$ than $\mathrm{DM}$ production in all the other cultivars.

Table 3. Shoot dry mater production during the first and second experimental periods; root DM/shoot DM ratio, leaf weight ratio (LWR), specific leaf area (SLA), and leaf area ratio (LAR) evaluated during the second experimental period in seven Lotus corniculatus cultivars exposed to two water treatments (NWS and WWS, without or with water stress, respectively) under greenhouse conditions.

\begin{tabular}{|c|c|c|c|c|c|c|c|c|c|}
\hline \multirow[b]{3}{*}{ Cultivars } & \multicolumn{4}{|c|}{ Shoot DM production } & \multirow{2}{*}{\multicolumn{2}{|c|}{$\begin{array}{c}\text { Root DM/Shoot } \\
\text { DM }\end{array}$}} & \multirow[b]{3}{*}{ LWR } & \multirow[b]{3}{*}{ SLA } & \multirow[b]{3}{*}{ LAR } \\
\hline & \multicolumn{2}{|c|}{ Exp. Period I } & \multicolumn{2}{|c|}{ Exp. Period II } & & & & & \\
\hline & NWS & WWS & NWS & WWS & NWS & WWS & & & \\
\hline & 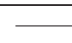 & 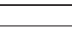 & & - & & & & 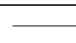 & 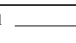 \\
\hline San Gabriel & 5.47 & 1.67 & 7.36 & 1.68 & 0.52 & 0.70 & 0.49 & 238.1 & 116.48 \\
\hline Quimey & 5.52 & 2.12 & 7.19 & 2.05 & 0.49 & 0.73 & 0.48 & 228.9 & 108.25 \\
\hline Ganador & 4.32 & 1.33 & 5.58 & 2.13 & 0.40 & 0.66 & 0.52 & 223.1 & 116.44 \\
\hline Empire & 2.30 & 0.54 & 5.36 & 0.91 & 0.44 & 0.83 & 0.52 & 248.4 & 130.74 \\
\hline Steadfast & 2.76 & 0.78 & 5.72 & 1.16 & 0.49 & 1.00 & 0.54 & 223.4 & 119.62 \\
\hline GES-5 & 3.06 & 0.92 & 5.42 & 1.24 & 0.41 & 0.74 & 0.48 & 222.6 & 107.91 \\
\hline Norcen & 2.92 & 0.81 & 5.84 & 1.32 & 0.61 & 0.95 & 0.57 & 248.9 & 142.68 \\
\hline Significance & $* * *$ & & $*$ & & * & & $* * *$ & ns & * \\
\hline \multirow[t]{6}{*}{$\underline{\mathrm{LSD}}$} & 0.73 & & 0.80 & & 0.132 & & 0.037 & ns & 23.06 \\
\hline & & & \multicolumn{4}{|c|}{ Water treatments } & & & \\
\hline & & & \multicolumn{4}{|c|}{ NWS } & 0.50 & 274.4 & 139.0 \\
\hline & & & \multicolumn{4}{|c|}{ WWS } & 0.53 & 189.6 & 100.4 \\
\hline & & & \multicolumn{4}{|c|}{ Significance } & $*$ & $* * *$ & $* * *$ \\
\hline & & & \multicolumn{4}{|c|}{ LSD } & 0.020 & 20.47 & 12.40 \\
\hline
\end{tabular}

Significant at $* \mathrm{P}<0.05, * * \mathrm{P}<0.01$, and $* * * \mathrm{P}<0.001 ;$ ns: nonsignificant; LSD: least significant difference. 
The situation was similar for the WWS treatment, but only DM production in 'Quimey' and 'San Gabriel' was significantly different from all other cultivars (Table 3). The decrease in DM production during the second experimental period for the WWS treatment was similar to values observed in the first period. 'Quimey' and 'San Gabriel' in the NWS treatment significantly outperformed the other cultivars for DM production. 'Quimey' and 'Ganador' had the highest DM production in the WWS treatment and were significantly different from the cultivar with the lowest DM production ('Empire').

Soil water availability affected biomass partitioning of all cultivars under study. The root/shoot DM ratio showed a significant interaction among cultivars and soil water treatments $(\mathrm{P}<0.05$; Table 3$)$. All cultivars showed a significant increase in root/shoot DM in the WWS treatment compared to in the NWS treatment. The leaf-area ratio $(\mathrm{LAR}=\mathrm{LWR} \times \mathrm{SLA})$ varied significantly between water treatments and among cultivars (Table 3). The LAR decreased by almost $30 \%$ in the WWS treatment compared to in the NWS treatment. Variations in LAR were caused only by the different capacity of the cultivars to partition biomass to the leaves (LWR), because no significant differences were observed in SLA ( $>$ > 0.05; Table 3).

\section{Osmotic adjustment and water use efficiency}

Xylem water potential was evaluated three times during the experiment and decreased almost six-fold at 23 DAP and by more than $90 \%$ at 49 and 56 DAP in the WWS treatment compared with the NWS treatment. The decrease in $\Psi_{\mathrm{x}}$ was not lethal for the plant but affected its transpiration rate and biomass production and partitioning (Table 3). However, under drought conditions (WWS), all the L. corniculatus cultivars showed a significant difference in $\Psi_{\mathrm{x}}$ components $(\mathrm{P}<0.001)$, according to the conceptual definition of OA. On average, $\Psi_{\pi}$ decreased by $60 \%$ on the three sampling dates, but $\Psi_{\mathrm{p}}$ increased by approximately $30 \%$ in the WWS treatment compared with the NWS treatment (Table 2). These results lead to the conclusion that $L$. corniculatus strongly induces OA under drought conditions. However, the decrease in $\Psi_{\pi}$ and increase in $\Psi_{\mathrm{p}}$ are significantly related $(\mathrm{P}<0.05)$ to a decrease in DM production (Figure 3).

Water-use efficiency, calculated for each experimental period, varied significantly between soil-water treatments and among cultivars $(\mathrm{P}<0.05)$. Water-use efficiency in both periods decreased by approximately $30 \%$ in the WWS treatment compared to in the NWS treatment and the cultivars with the highest and lowest WUE were 'Quimey' and 'Empire', respectively (Figures 4 and 5). However, WUE was strongly associated with DM production under water stress conditions (WWS) in both evaluation periods $\left(\mathrm{P}<0.05 ; R^{2}=0.88\right.$; Figure 4$)$.

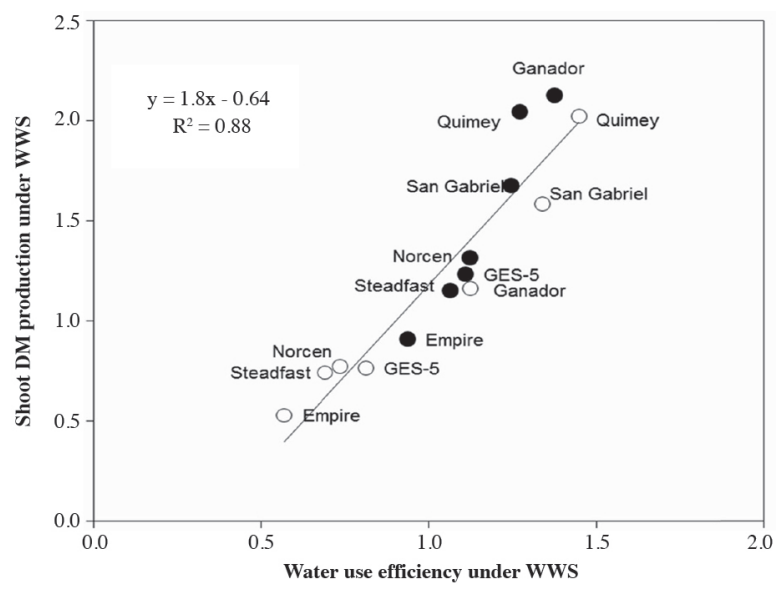

Figure 4. Relationship between shoot dry mater (DM) production and water-use efficiency under water stress conditions (WWS) evaluated during the first (black circle) and second (white circle) experimental periods.

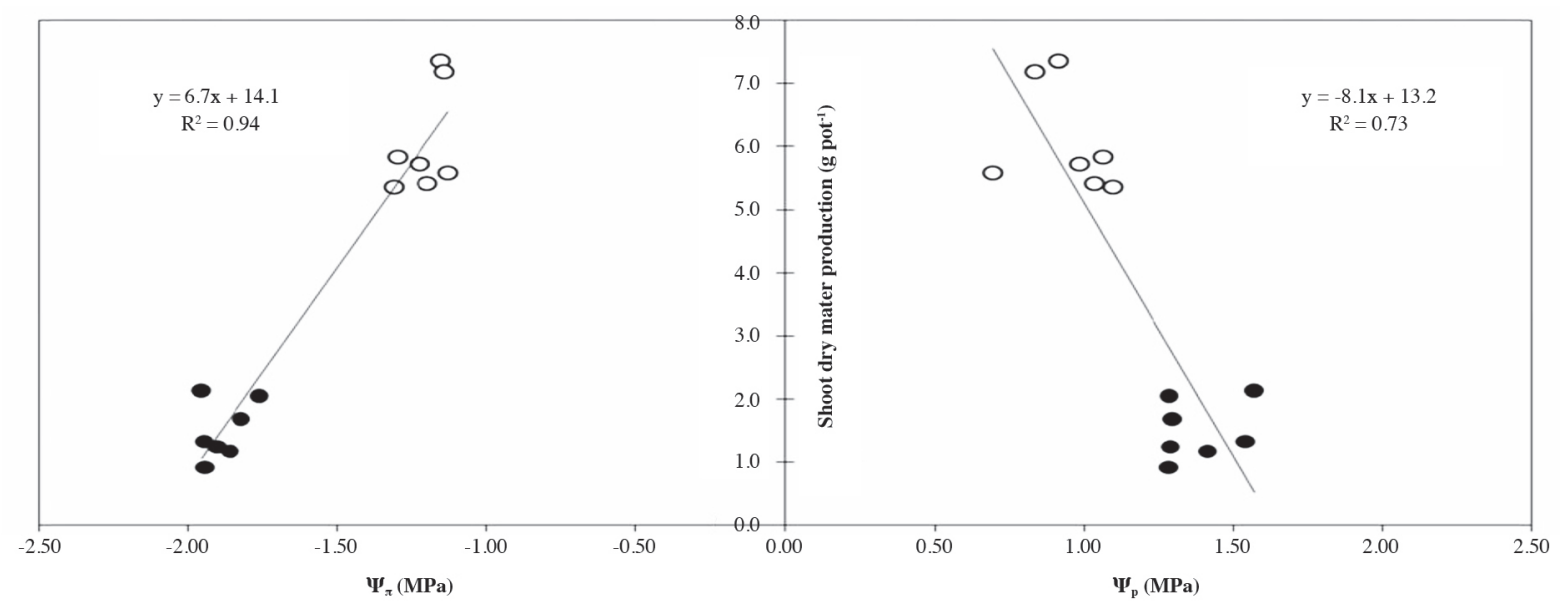

Figure 3. Relationship between shoot dry mater production and osmotic $\left(\Psi_{\pi}\right)$ and pressure $\left(\Psi_{\mathrm{p}}\right)$ potential of seven Lotus corniculatus cultivars subjected to two soil water treatments under greenhouse conditions: with water stress (black circle) or no water stress (white circle). Data from the second experimental period. 


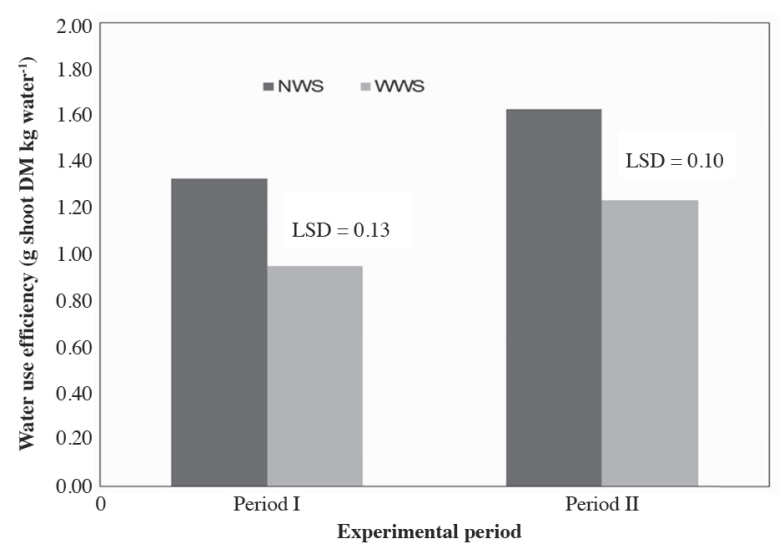

Period I (from planting to first cutting; $30 \mathrm{~d}$ ); Period II (27 d after first cutting)

Figure 5. Water-use efficiency evaluated in two experimental periods (period I and period II) of Lotus corniculatus subjected to two soil water treatments (NWS and WWS, without or with water stress, respectively). Values are means of seven cultivars. LSD: least significant difference.

\section{DISCUSSION}

\section{Drought acclimation}

Plant water deficits can occur as a consequence of a seasonal decline in soil water availability in the long term or can result from drought spells. The timing, intensity, and duration of stress episodes are fundamental for determining the effects produced by drought (Chaves and Oliveira, 2004). The present study was therefore designed to simulate drought that was typical of Mediterranean environments and occurs when pastures are already established and the plant is completely developed. Moreover, the perception of stress is gradual and depends on the soil water-holding capacity and atmospheric evaporative demand. The results show this gradual entry to the WWS treatment, where pots took $15 \mathrm{~d}$ to attain the water treatment (Figure 1). The seven L. corniculatus cultivars began to acclimate within this period, which included a sharp decrease in the plant water status $\left(\Psi_{\mathrm{x}}\right.$ and RWC), and a rapid decrease in the gas exchange rate $\left(\mathrm{g}_{\mathrm{s}}\right.$ and transpiration rate) for the time-scale of the experiment, because the transpiration rate at 5 DAP decreased by $15 \%$ in the WWS treatment compared to that in the NWS treatment (Figure 2) and decreased by $40 \%$ at 14 DAP, when all pots entered the WWS treatment (Table 1).

As mentioned, the acclimation process to drought was gradually induced in plants from an optimal water condition. Prior to water stress, plants had already developed leaves and stems that slowly modified their physiology to stress, but not their morphology (Table 2). The physiological response to drought (WWS) in this period was the same for all cultivars and consisted of a decrease in $\Psi_{\mathrm{x}}$ of approximately six-fold that observed in the NWS treatment. This was accompanied by an approximately $90 \%$ decrease in $\Psi_{\pi}$ and $80 \%$ increase in $\Psi_{\mathrm{p}}$ (Table 2). The regrowth process began following cutting and when plants were physiologically acclimated to drought and showed clear morphological modifications caused by alterations in the growth, development and partitioning of shoot biomass (LAR and LWR; Table 3). The interaction between physiological and morphological acclimation that occurred during the regrowth period, generated a phenotype of small and very turgid leaves (Tables 2 and 3). In general, this allowed $\Psi_{\mathrm{x}}$ values to stabilize at about- 0.28 and $-0.52 \mathrm{MPa}$ in the NWS and WWS treatments, respectively (Table 2); the difference between water treatments was three-fold lower than that observed during the first experimental period (Table 2).

Water relationships $\left(\Psi_{\mathrm{x}}=\Psi_{\pi}+\Psi_{\mathrm{p}}\right)$ were determined three times and the same response pattern was observed for all cultivars, which consisted of a decrease in $\Psi_{\mathrm{x}}$ and $\Psi_{\pi}$ and an increase in $\Psi_{\mathrm{p}}$ in the WWS treatment compared with the NWS treatment (Table 2). Despite maintaining this response pattern, significant differences were observed among cultivars $(\mathrm{P}<0.05)$ for transpiration rate, RWC, and $\mathrm{g}_{\mathrm{s}}$, which reflect specific physiological mechanisms of each cultivar and allow acclimation of its metabolism to drought conditions. For example, 'Quimey' in the WWS treatment showed one of the highest RWC values and the lowest $\mathrm{g}_{\mathrm{s}}$ values. Despite this physiological modification, 'Quimey' showed the highest accumulated T value during the first experimental period. This accounts for a watersaving strategy through a conservative gas exchange that allows an increase in its physiological $\left(\mathrm{CO}_{2} / \mathrm{H}_{2} \mathrm{O}\right)$ and agronomic WUE (Figure 4).

\section{The role of osmotic adjustment and water-use efficiency on DM production}

Plant strategies to control water status and resist drought are numerous (Chaves and Oliveira, 2004) and can be grouped into three categories: those allowing escape from drought by shortening the ontogenetic cycle (drought escape); those allowing the maintenance of plant water status and physiology under drought conditions (drought avoidance); and those allowing the maintenance of plant metabolic functions with a depressed water status (drought tolerance). In agronomy, whichever strategy should allow for continued or increased biomass production under water-deficit conditions. Strategies in perennial species such as L. corniculatus are concentrated in the second category, for which OA has been one of the most-studied physiological mechanisms in model and cultivated plants (Verslues and Bray, 2004; Blum, 2005; Maggio et al., 2006). The results of the present study are evidence of the high capacity of $L$. corniculatus to induce OA under drought conditions from the initial stage of the acclimation process (Table 1). Under drought conditions (WWS), all L. corniculatus cultivars modified the $\Psi_{\mathrm{x}}$ components according to the conceptual definition of OA. On average, $\Psi_{\pi}$ was reduced by $60 \%$ on the three 
sampling dates and $\Psi_{\mathrm{p}}$ increased by approximately $30 \%$ in the WWS treatment compared to in the NWS treatment (Table 2). The present study is the first to quantify the capacity to induce OA in L. corniculatus in physical terms (water potential). Using a non-targeted metabolomic approach, Sanchez et al. (2012) recently studied the kinetics of accumulating solutes in a model and a forage Lotus species subjected to drought. Their results confirm the high capacity for $L$. corniculatus to perform OA and extends this conclusion to all species of the Lotus genus that are agronomically important (L. tenuis and $L$. uliginosus), since the osmolyte concentration increased in all species under drought conditions.

Similar to L. corniculatus, several plant species of agricultural importance have the capacity to carry out OA under drought conditions (Turner, 1990; Morgan, 1995; Babu et al., 1999; Turner et al., 2007). However, the role of $\mathrm{OA}$ in conferring productive stability under drought conditions has been controversial to date. For instance, the study by Turner et al. (2007) concluded that differences in OA were not associated with yield benefits in a population of advanced breeding lines of chickpea that were developed from a cross between cultivars with high and low OA, similar results has been reported in barley (Chen et al., 2007; Widodo et al., 2009) and potatoes (Vasquez-Robinet et al., 2008). On the other hand, wheat possesses considerable genetic variability to carry out OA and cultivars with a high OA capacity exhibit higher yield under water stress conditions than cultivars with a low OA capacity (Morgan, 1995; El Hafid et al., 1998; Blum et al., 1999). Under drought conditions, the results of the present study show that the increase in the accumulation of solutes in L. corniculatus (lowest $\Psi_{\pi}$ value) caused by water stress is associated with a sharp decrease in DM production (Figure 3). The cultivars with the most divergent $\Psi_{\pi}$ values on all the sampling dates were 'Quimey' and 'Empire' (Table 2). These cultivars also showed the highest and lowest DM production, respectively, in both experimental periods (Table 3). Accordingly, OA in L. corniculatus is a component of its drought tolerance, since it allows the maintenance or even an increase in $\Psi_{\mathrm{p}}$ in acclimated plants under water-deficit conditions. This provides continuity in gas exchange ( $\mathrm{T}$ and $\mathrm{g}_{\mathrm{s}}$ ), growth, and biomass accumulation (Tables 1 and 3), but overexpression of the mechanism is associated with a lower DM production under drought conditions (Figure 3 and Table 1). In this respect, the physiological mechanism only supports plant survival and not productivity under drought conditions, which coincides with the results observed in chickpea by Turner et al. (2007).

The values of $\Psi_{\mathrm{p}}$ showed no significant differences among cultivars in the three evaluations (23, 49, and 56 DAP; Table 2). However, $\Psi_{\mathrm{p}}$ values under water-stress conditions (WWS) were unexpectedly higher than those observed under control conditions (NWS; Table 2).
Thus, L. corniculatus had a lower growth and biomass accumulation in WWS, with $\Psi_{\mathrm{p}}$ values higher than those obtained in NWS (Tables 2 and 3). These results contradict the historically accepted theory formulated by Lockhart (1965), who established a first-order relationship between turgor $\left(\Psi_{\mathrm{p}}\right)$ and cell growth, which is expressed as $E=$ $m(P-Y)$, where $E$ is expansive growth, $m$ is the cell elasticity coefficient, $P$ is cell turgor, and $Y$ is the turgor pressure at which cell expansion begins. This relationship indicates that any factor that modifies plant water status and reduces turgor pressure $\left(\Psi_{\mathrm{p}}\right)$, such as drought or salinity, reduces cell growth. Studies subsequent to the Lockhart equation establish the existence of a linear relationship between plant growth and turgor (Passioura and Fry, 1992). However, background information supporting the most recent plant growth theories indicates that cell elongation no longer depends on turgor (Maggio et al., 2006). Bressan et al. (1990) demonstrated that after an acclimation period to osmotic stress, the relationship between cell division and elongation is altered and is not controlled by turgor or the osmotic status of the cell; this indicates that there must be proactive genetic control of the integrated growth process that can be reset after osmotic stress acclimation and which results in slower growth with equal or higher turgor levels.

Another relevant factor in maintaining and/or increasing turgor $\left(\Psi_{\mathrm{p}}\right)$ of $L$. corniculatus under drought conditions was its capacity to modify leaf size. The leaf area ratio decreased by approximately $30 \%$ under drought conditions (WWS) compared with the control treatment (NWS), which was associated with a sharp decrease in SLA and a modification in aerial biomass partitioning. The latter is expressed as an increase in LWR in WWS compared with NWS (Table 3). This phenotypic plasticity resulted in smaller-sized, but very turgid leaves under water-stress conditions. Similar results were reported by Inostroza and Acuña (2010) for white clover and Acuña et al. (2010) for L. tenuis.

Water-use efficiency was estimated in two growth periods and significant differences were observed in both periods among cultivars and a close relationship between WUE and shoot DM production under water stress conditions was found (Figure 4). Cultivars with divergent WUE were 'Quimey' and 'Empire', with the highest and lowest WUE value and DM production, respectively, under water stress conditions (Figure 4). Unlike species such as wheat (Condon et al., 2004) and white clover (Inostroza and Acuña, 2010), the WUE of L. corniculatus decreases significantly $(\mathrm{P}<0.001)$ under WWS conditions compared to the control (NWS; Figure 5). Carter et al. (1997) evaluated WUE in L. corniculatus with a methodology similar to the one used in the present study and observed that it was not affected by water treatment. Both findings are of great importance in the breeding of cultivated species and provide information concerning the recent controversy over the relationship 
between WUE and yields under water-stress conditions. Blum $(2005 ; 2009)$ argued that high yield potential and high yield under water-limiting conditions are generally associated with reduced WUE, mainly because of high water use (transpiration). Accordingly, any phenotypic trait that increases water-use under drought conditions will also increase yield under stress. In contrast, phenotypic traits linked to low yield potential, such as smaller plants or a short duration of growth, have a high WUE because they reduce water use and yield. Blum's (2005; 2009) argument contradicts current views, which is strongly supported by theoretical and empirical studies (Richards et al., 2002; Condon et al., 2004), where a high WUE is associated with highly productive genotypes under drought conditions; this coincides with the results obtained in this study (Figure 4). The cultivar with the highest water use and DM yield under drought conditions (WWS) was 'Quimey', and this coincides with Blum's (2005 and 2009) arguments. 'Quimey' was also the cultivar with the highest WUE. Given our results, the water use and DM yield of L. corniculatus sharply decreases under drought conditions compared with the control treatment, but yield reduction was higher $(-75 \%)$ than the water-use reduction $(-65 \%)$. For this reason, WUE was lower in WWS than in NWS conditions (Tables 1 and 3; Figure 5). Considerable variability in WUE and its components was observed (water use and DM yield) under drought conditions (WWS) among the seven cultivars under study; those that captured more water achieved a higher yield and thus a higher WUE (Figure 4).

\section{CONCLUSION}

In conclusion, Lotus corniculatus exhibits a high capacity to induce osmotic adjustment (OA) under drought conditions. This is an intrinsic characteristic of the species since all the cultivars evaluated in the present study, originating from five countries on two continents, showed the same ability. Those cultivars that showed a higher accumulation of solutes under drought conditions (lower $\left.\Psi_{\pi}\right)$ were negatively affected in their DM production. In this respect, OA only accomplishes a relevant role in the plant's survival capacity under stress conditions. On the other hand, under water stress (WWS) conditions, cultivars that had the highest water-use efficiency (WUE) produced the highest DM yield due to an acclimation strategy with the objective of maintaining water status $\left(\Psi_{\mathrm{p}}\right)$ and ensuring continuous gas exchange ( $\mathrm{T}$ or water use). The strategy is based on saving water, where stomatal conductance $\left(\mathrm{g}_{\mathrm{s}}\right)$ plays a fundamental role, but is not the only factor, and also includes a decrease in the transpiration area (specific leaf area and leaf-area ratio), a reduction in gas exchange ( $g_{s}$ and transpiration rate), a modification of aerial biomass partitioning (leaf-weight ratio), and the maintenance of cell turgor $\left(\Psi_{\mathrm{p}}\right)$ by OA. Together, these generate a phenotype with small and very turgid leaves that allow the maintenance of plant growth under drought conditions.

\section{ACKNOWLEDGEMENTS}

This study was supported by a grant from INIA (project ID 501364-70) and VI Framework Program of European Union (Lotassa Project). We thank Celerino Quezada, from the Universidad de Concepción, and his thesis student Heriberto Rivera for their scientific and technical help.

\section{LITERATURE CITED}

Acuña, H., M Figueroa, A.D.L. Fuente, y C. Fuentes. 2002. Comportamiento de cvs. de Lotus corniculatus L. en diferentes ambientes de la VIII y IX Regiones de Chile. Agro-Ciencia 18:75-84.

Acuña, H., L. Inostroza, M.A.P. Sánchez, and G. Tapia. 2010. Drought-tolerant naturalized populations of Lotus tenuis for constrained environments. Acta Agriculturae Scandinavica, Section B - Plant Soil Science. 60:174-181

Babu, R.C., M.S. Pathan, A. Blum, and H.T. Nguyen. 1999. Comparison of measurement methods of osmotic adjustment in rice cultivars. Crop Science 39:150-158.

Blum, A. 2005. Drought resistance, water-use efficiency, and yield potential-are they compatible, dissonant, or mutually exclusive? Australian Journal of Agricultural Research 56:1159-1168.

Blum, A. 2009. Effective use of water (EUW) and not water-use efficiency (WUE) is the target of crop yield improvement under drought stress. Field Crops Research 112:119-123.

Blum, A., J. Zhang, and H.T. Nguyen. 1999. Consistent differences among wheat cultivars in osmotic adjustment and their relationship to plant production. Field Crops Research 64:287-291.

Borsani, O., P. Díaz, M.F. Agius, V. Valpuesta, and J. Monza. 2001. Water stress generates an oxidative stress through the induction of a specific $\mathrm{Cu} / \mathrm{Zn}$ superoxide dismutase in Lotus corniculatus leaves. Plant Science 161:757-763.

Bressan, R., D. Nelson, N. Iraki, C.L. Rosa, N. Singh, P. Hasegawa, et al. 1990. Reduced cell expansion and changes in cell walls of plant cells adapted to NaCl. p. 137-171. In Katterman, F. (ed.) Environmental injury to plants. Academic Press, San Diego, California, USA.

Carter, E., M. Theodorou, and P. Morris. 1997. Responses of Lotus corniculatus to environmental change. I. Effects of elevated $\mathrm{CO}_{2}$, temperature and drought on growth and plant development. New Phytologist 136:245-253

Cattivelli, L., F. Rizza, F.-W. Badeck, E. Mazzucotelli, A.M. Mastrangelo, E. Francia, et al. 2008. Drought tolerance improvement in crop plants: An integrated view from breeding to genomics. Field Crops Research 105:1-14.

Chaves, M.M., and M.M. Oliveira. 2004. Mechanisms underlying plant resilience to water deficits: Prospects for water-saving agriculture. Journal of Experimental Botany 55:2365-2384.

Chen, Z., T.A. Cuin, M. Zhou, A. Twomey, B.P. Naidu, and S. Shabala. 2007. Compatible solute accumulation and stressmitigating effects in barley genotypes contrasting in their salt tolerance. Journal of Experimental Botany 58:4245-4255.

Cobb, J., G. DeClerck, A. Greenberg, R. Clark, and S. McCouch. 2013. Next-generation phenotyping: requirements and strategies for enhancing our understanding of genotype-phenotype relationships and its relevance to crop improvement. Theoretical and Applied Genetics 126:867-887.

Condon, A.G., R.A. Richards, G.J. Rebetzke, and G.D. Farquhar. 2004. Breeding for high water-use efficiency. Journal of Experimental Botany 55:2447-2460. 
Earl, H.J. 2002. Stomatal and non-stomatal restrictions to carbon assimilation in soybean (Glycine max) lines differing in water use efficiency. Environmental and Experimental Botany 48:237-246.

El Hafid, R., D.H. Smith, M. Karrou, and K. Samir. 1998 Physiological responses of spring durum wheat cultivars to early-season drought in a Mediterranean environment. Annals of Botany 81:363-370.

Garcia, I., R. Mendoza, and M.C. Pomar. 2008. Deficit and excess of soil water impact on plant growth of Lotus tenuis by affecting nutrient uptake and arbuscular mycorrhizal symbiosis. Plant and Soil 304:117-131.

Inostroza, L., and H. Acuña. 2010. Water use efficiency and associated physiological traits of nine naturalized white clover populations in Chile. Plant Breeding 129:700-706.

Kirkbride, J. 1999. Lotus systematics and distribution. p. 1-20. In Beuselinck, P.R. (ed.) Trefoil: The science and technology of lotus. American Society of Agronomy, Crop Science Society of America, Madison, Wisconsin, USA.

Kraakman, A.T.W., R.E. Niks, P.M. Van den Berg, P. Stam, and F.A. van Eeuwijk. 2004. Linkage disequilibrium mapping of yield and yield stability in modern spring barley cultivars. Genetics and Molecular Biology 168:435-446.

Lockhart, J.A. 1965. An analysis of irreversible plant cell elongation. Journal of Theoretical Biology 8:264-275.

Maggio, A., J.-K. Zhu, P.M. Hasegawa, and R.A. Bressan. 2006. Osmogenetics: Aristotle to Arabidopsis. The Plant Cell Online 18:1542-1557.

Manzur, M.E., A.A. Grimoldi, P. Insausti, and G.G. Striker. 2009. Escape from water or remain quiescent? Lotus tenuis changes its strategy depending on depth of submergence. Annals of Botany 104:1163-1169.

Morgan, J.M. 1995. Growth and yield of wheat lines with differing osmoregulative capacity at high soil water deficit in seasons of varying evaporative demand. Field Crops Research 40:143-152.

Neal, J.S., W.J. Fulkerson, and B.G. Sutton. 2011. Differences in water-use efficiency among perennial forages used by the dairy industry under optimum and deficit irrigation. Irrigation Science 29:213-232.

Passioura, J.B., and S.C. Fry. 1992. Turgor and cell expansion: Beyond the Lockhart equation. Functional Plant Biology 19:565-576.

Real, D., J. Warden, G.A. Sandral, and T.D. Colmer. 2008 Waterlogging tolerance and recovery of 10 Lotus species Australian Journal of Experimental Agriculture 48:480-487.

Rebetzke, G.J., A.G. Condon, R.A. Richards, and G.D. Farquhar. 2002. Selection for reduced carbon isotope discrimination increases aerial biomass and grain yield of rainfed bread wheat. Crop Science 42:739-745.

Richards, R.A., G.J. Rebetzke, A.G. Condon, and A.F. Herwaarden. 2002. Breeding opportunities for increasing the efficiency of water use and crop yield in temperate cereals. Crop Science 42:111-121.
Sanchez, D.H., F. Lippold, H. Redestig, M.A. Hannah, A. Erban, U. Kramer, et al. 2008. Integrative functional genomics of salt acclimatization in the model legume Lotus japonicus. Plant Journal 53:973-987.

Sanchez, D.H., F. Schwabe, A. Erban, M.K. Udvardi, and J. Kopka. 2012. Comparative metabolomics of drought acclimation in model and forage legumes. Plant, Cell \& Environment 35:136-149.

Sinclair, T.R., L.C. Purcell, and C.H. Sneller. 2004. Crop transformation and the challenge to increase yield potential. Trends in Plant Science 9:70-75.

Striker, G.G., P. Insausti, A.A. Grimoldi, E.L. Ploschuk, and V. Vasellati. 2005. Physiological and anatomical basis of differential tolerance to soil flooding of Lotus corniculatus L. and Lotus glaber Mill. Plant and Soil 276:301-311.

Striker, G.G., R.F. Izaguirre, M.E. Manzur, and A.A. Grimoldi. 2012 Different strategies of Lotus japonicus, L. corniculatus and L. tenuis to deal with complete submergence at seedling stage. Plant Biology 14:50-55.

Teakle, N.L., A. Amtmann, D. Real, and T.D. Colmer. 2010. Lotus tenuis tolerates combined salinity and waterlogging: maintaining $\mathrm{O}_{2}$ transport to roots and expression of an NHX1-like gene contribute to regulation of $\mathrm{Na}^{+}$transport. Physiologia Plantarum 139:358-374

Teakle, N.L., T.J. Flowers, D. Real, and T.D. Colmer. 2007. Lotus tenuis tolerates the interactive effects of salinity and waterlogging by 'excluding' $\mathrm{Na}^{+}$and $\mathrm{Cl}^{-}$from the xylem. Journal of Experimental Botany 58:2169-2180.

Teakle, N.L., D. Real, and T.D. Colmer. 2006. Growth and ion relations in response to combined salinity and waterlogging in the perennial forage legumes Lotus corniculatus and Lotus tenuis. Plant and Soil 289:369-383.

Turner, L.B. 1990. The extent and pattern of osmotic adjustment in white clover (Trifolium repens L.) during the development of water stress. Annals of Botany 66:721-727.

Turner, N.C., S. Abbo, J.D. Berger, S.K. Chaturvedi, R.J. French, C. Ludwig, et al. 2007. Osmotic adjustment in chickpea (Cicer arietinum L.) results in no yield benefit under terminal drought. Journal of Experimental Botany 58:187-194.

Vasquez-Robinet, C., S.P. Mane, A.V. Ulanov, J.I. Watkinson, V.K. Stromberg, D. De Koeyer, et al. 2008. Physiological and molecular adaptations to drought in Andean potato genotypes. Journal of Experimental Botany 59:2109-2123.

Verslues, P.E., and E.A. Bray. 2004. LWR1 and LWR2 are required for osmoregulation and osmotic adjustment in Arabidopsis. Plant Physiology 136:2831-2842.

Widodo, M.A., J.H. Patterson, E. Newbigin, M. Tester, A. Bacic and U. Roessner. 2009. Metabolic responses to salt stress of barley (Hordeum vulgare L.) cultivars, Sahara and Clipper, which differ in salinity tolerance. Journal of Experimental Botany 60:4089-4103. 